\title{
Beyond empty promises? A reality check for hate crime scholarship and policy
}

\author{
Neil Chakraborti and Stevie-Jade Hardy
}

Neil Chakraborti is a Professor in Criminology and

Stevie-Jade Hardy is a Lecturer in Hate Studies, both at the Department of Criminology, University of Leicester, Leicester, UK.
Received 13 June 2017 Accepted 11 July 2017

(C) Neil Chakraborti and Stevie-Jade Hardy. Published by Emerald Publishing Limited. This article is published under the Creative Commons Attribution (CC BY 4.0) licence. Anyone may reproduce, distribute, translate and create derivative works of this article (for both commercial and non-commercial purposes), subject to full attribution to the original publication and authors. The full terms of this licence may be seen at http://creativecommons. org/licences/by/4.0/legalcode This work was supported by the Economic and Social Research Council (grant number

ES/J008109/1) and by funding awarded by the Equality and Human Rights Commission, and the Offices for the Police and Crime Commissioner in Hertfordshire and the West Midlands.

\begin{abstract}
Purpose - The purpose of this paper is to highlight an urgent need for new and improved approaches to supporting hate crime victims and tackling hate crime perpetration in the light of escalating levels of hate crime and growing concerns over the effectiveness of existing interventions and support structures.

Design/methodology/approach - The paper draws from the authors' own extensive fieldwork conducted with more than 2,000 victims of hate crime over a series of recent studies. The research was designed to uncover lived experiences of hate crime, to understand the physical and emotional harms suffered by victims and their families, and to identify ways of improving the quality of support offered to victims.

Findings - The findings illustrate that current responses to hate crime are hampered by a range of perceived challenges and barriers to justice which exacerbate the harms associated with hate crimes. This includes low levels of public awareness of relevant policies, laws and support services, a lack of meaningful engagement between professionals and marginalised communities and a failure to provide victim-centred criminal justice interventions.

Practical implications - This paper includes a number of recommendations in relation to how scholars, policy makers and professionals can overcome the failings that have been identified, which includes prioritising engagement with diverse communities, improving awareness of hate crime and generating a more comprehensive evidence base on hate crime perpetration.

Originality/value - These themes discussed within this paper are based upon the views and experiences of an extensive sample of hate crime victims, many of whom have never previously shared their stories with researchers, the police or any other support organisations.
\end{abstract}

Keywords Diversity, Victims, Hate crime, Marginalization, Criminal justice policy, Targeted hostility

Paper type Research paper

\section{Introduction}

In the months following the June 2016 EU referendum, the UK experienced an unprecedented surge in reports of hate crime. In excess of 14,000 hate crimes were recorded by police forces in England and Wales between July and September 2016, with three-quarters of forces reporting record levels of hate crime during that period (BBC News, 2017). Hate incidents have continued to escalate in the aftermath of recent terrorist attacks in Manchester and London, with evidence suggesting that "trigger" events of local, national and international significance can influence the prevalence and severity of hate incidents within cyberspace and the physical world (Awan and Zempi, 2017). This rise is rooted too within a wider, structural process whereby attacks against the "other" can feed off economic instability, political scaremongering and media stereotyping to the point where violence becomes a mechanism used to reinforce power dynamics between dominant and subordinate groups and to create cultures of fear within marginalised communities (Chakraborti and Garland, 2012; Perry, 2001).

During the past two decades, a series of steps have been taken by law-makers, non-governmental organisations, activists and professionals within and beyond the criminal justice sector to develop improved responses to hate crime through the introduction of relevant legislation and evidence-based policy guidance. However, this paper reveals that those developments have been only partially effective in addressing real-life needs. Instead, the damage caused by hate crime can often be overlooked as a result of disconnects between state-level narratives and victims' lived 
realities, and through a failure to translate empirical and policy progress beyond empty promises and into meaningful action for some of the most stigmatised and marginalised members of society. The paper draws from a series of recent studies conducted by the authors which uncovered the experiences and perceptions of an overall sample which consisted of more than 2,000 hate crime victims from a diverse range of backgrounds and which included victims who had been targeted on the basis of having multiple identity characteristics and on multiple occasions.

The first of these studies - the Leicester Hate Crime Project - was a two-year piece of research funded by the Economic and Social Research Council. A total of 1,106 victims of hate crime aged 16 and over shared their experiences and perceptions through completion of online or hard copy surveys, while 374 victims took part in in-depth, semi-structured interviews. The profile of research participants was diverse in terms of their age, gender identity, ethnicity, religion, sexual orientation and disabilities, and included sizeable numbers of participants from "hidden" or emerging communities including members of recently arrived migrant groups, victims targeted because of their "different" modes of dress, appearance or lifestyle and people with learning disabilities and/or mental ill-health. The second study, funded by the Equality and Human Rights Commission, focused specifically on the experiences of 50 lesbian, gay, bisexual and transsexual (LGBT) victims of hate crime based in Leicester and Leicestershire. Again, the sample was made up of a diverse profile of ages, ethnicities and socio-economic backgrounds and included victims who described themselves as having a range of overlapping identity characteristics, such as being gay and Muslim, or being trans and physically disabled. The third study was commissioned by the Office for the Police and Crime Commissioner (OPCC) in Hertfordshire and was based on the perceptions and experiences of 1,652 actual and at-risk victims of hate crime through responses to online and hard copy questionnaire surveys $(n=1,604)$ and in-depth interviews $(n=81)[1]$. This approach was mirrored within the final study referred to within this paper, which was conducted on behalf of the OPCC in the West Midlands. A diverse sample of 373 people took part in the West Midlands-based study through participation in an online or hard copy survey $(n=360)$ or through an interview $(n=45)$.

Further details about each study, and their individual methodologies, findings and recommendations can be found elsewhere (Hardy and Chakraborti, 2017; 2016; Chakraborti and Hardy, 2015; Chakraborti et al., 2014). For the purposes of this paper, relevant analysis from each study is presented collectively to identify common failings in relation to meeting the needs of hate crime victims and facilitating access to justice. Before turning to this analysis, the paper first presents a necessarily brief outline of the policy framework in place to address hate crime domestically in order to offer context to the findings which follow.

\section{Signs of progress within the domains of hate crime scholarship and policy}

Many different definitions of hate crime can be found within the wider literature and almost all refer to a broader range of factors than hate alone to describe the motivation that lies behind the commission of a hate crime (see, inter alia, Chakraborti et al., 2014; Hall, 2013; Chakraborti and Garland, 2012; Perry, 2001). These academic contributions have used terms such as "targeted hostility", "prejudice" and "bias" to highlight that the presence of "hate" itself is not central to the commission of a hate crime and have illustrated the relationship between structural hierarchies, institutionalised prejudices and acts of hate. They have shown that some hate crime victims can be targeted because they are seen as being especially vulnerable or "different" in the eyes of the perpetrator through the interplay of multiple identity characteristics, situational factors and prevailing social and economic conditions within different micro-spaces. These academic contributions have also highlighted the multiple layers of harm associated with hate offences which commonly include excessive physical violence and brutality, emotional damage, psychological scars and the escalation of social tensions (see also Iganski and Lagou, 2015; Office for Democratic Institutions and Human Rights (ODIHR), 2009).

Beyond the academic domain, notable efforts have been made to generate a consistent approach to hate crime policy formation within the UK. College of Policing (2014) guidance requires the police to record and investigate any hate incident perceived by the victim or any other person (such as a witness, a family member or a carer) as being motivated by hostility or prejudice towards any one of the five monitored strands of identity, namely, disability, race, religion, sexual orientation and transgender status. Most domestic hate crime policy is based around these five 
strands, although the same guidance gives police forces the licence to think beyond those strands and, where appropriate, to record other forms of targeted hostility as hate crime in response to regional needs or priorities. This has enabled a number of forces to monitor other offences - including violence against alternative subcultures and sex workers, and more recently misogynistic harassment - as additional strands of hate crime within their local areas (Mason-Bish, 2016; Garland and Hodkinson, 2015; Campbell, 2014).

These developments within the domains of policy and scholarship have been supported at the state level through the introduction of hate crime laws which allow for "enhanced" sentences to be imposed in relation to offences which have been aggravated by hostility towards the victim's identity (for a fuller review, see Law Commission, 2014), and by successive UK Government Action Plans (Home Office, 2016; HM Government, 2012) which are designed to reinforce the state's commitment to tackling hate crime. The most recent of these, "Action Against Hate", was published in the wake of the post-Brexit rise in recorded hate incidents across many parts of England and Wales (Home Office, 2016). However, while this Action Plan presents laudable aims in relation to prevention, reduction and support for victims, it fails to cover how these goals will be achieved and evaluated, or how the empirical evidence produced by academic research will be used to promote best practice (Walters and Brown, 2016). As such, and often despite the very best of intentions, academic research and policy can often have limited value to those directly affected by hate crime. Indeed, despite the growth of empirical contributions, a flurry of policy interventions and an apparent increase in state prioritisation, we are living in times where levels of hate crime have reached at an all-time high, where many victims are unwilling to report hate crime and where victim satisfaction with the handling of cases is lower for hate crime than it is for other crime types (see, inter alia, Corcoran et al., 2015; Chakraborti et al., 2014). With this backdrop in mind, the paper now draws from the authors' own fieldwork to illustrate a set of perceived failings, challenges and barriers to justice which serve to undermine the effectiveness of existing interventions.

\section{Problems in relation to reporting and engagement}

Responses to hate crime are contingent on incidents being reported by the victim or any other person present. The importance of reporting in the context of generating effective prioritisation and service delivery is well documented (Chakraborti and Garland, 2015; HM Government, 2014) but the disparity between the number of police-recorded hate incidents, which in 2015-2016 was 62,528, and the corresponding Crime Survey for England and Wales (CSEW) figure of 222,000 (Corcoran and Smith, 2016) suggests that many cases go unreported. This was certainly a theme within our research. Within The Leicester Hate Crime Project, for instance, fewer than one in four participants had reported their experiences of hate crime to the police (24 per cent; $n=265$ ) and fewer still had shared their experiences with a teacher (4 per cent; $n=47)$, victim support ( 3 per cent; $n=31$ ), their local authority ( 3 per cent; $n=28$ ) or a social care worker (2 per cent; $n=20$ ) (Chakraborti et al., 2014). Only 1 per cent of participants had contacted a community support organisation, such as an LGBT, disability or race equality network, while none had ever utilised any of the third-party reporting options available through local libraries or online, despite third-party reporting schemes being promoted within successive Government Hate Crime Action Plans (Home Office, 2016; HM Government, 2014).

In order to improve hate crime reporting rates, policy makers and professionals need to improve their understanding of the different barriers that communities and groups encounter, and to develop solutions to overcome them. Within our studies, one of the most frequently cited barriers to reporting was a shared perception amongst all strands of hate crime victims that they would not be taken seriously. This tended to be expressed most commonly by those victims who had been subjected to "everyday" forms of targeted hostility, including name-calling and other forms of intimidatory behaviour. For example, in our most recent study, 76 per cent $(n=240)$ of participants stated that they would be "unlikely" or "highly unlikely" to report being verbally abused to the police and 49 per cent $(n=156)$ were "unlikely" or "highly unlikely" to report being harassed in person or online (Hardy and Chakraborti, 2017).

Under-reporting has important implications for the uptake of support services. Within the context of hate crime, awareness of and access to support services is often dependent upon a victim being "signposted" to support by a public-sector agency. With so few hate crime victims coming 
forward to report their experience to the police or to a non-governmental organisation, the concern is that the majority of victims are effectively being denied access to much needed support by virtue of not being aware of its existence. Our research evidence suggests that fewer than 10 per cent of hate crime victims have accessed a support service as a result of their victimisation, with a lack of awareness of these services emerging as a significant contributory factor to this low uptake (Hardy and Chakraborti, 2016, 2017). Knowledge of hate crime policy, legislation and support was found to be especially limited within those communities who are socially, economically and politically marginalised within society, including asylum seekers and refugees, people with learning difficulties and/or physical disabilities and/or mental ill-health and transgender people (Chakraborti et al., 2014). More worrying still, this problem is only likely to become more entrenched in the current climate of economic instability, and through the enforced spending cuts to services and staffing within the public sector, as illustrated by these observations from practitioners and victims shared within our studies:

It seems to have got worse since the restructure. I personally don't feel we're doing very much at all for those victims [...]. You can't do meaningful engagement.

Cuts to specialised services are only making groups more and more vulnerable to attacks.

We're finding that because all of the funding is so restricted now, and all of the councils have had to make their cutbacks, what people used to be able to access isn't available anymore.

What's the point of reporting it? Nobody will pay attention to it, nobody will do anything about it.

Increasingly, the time and resource that professionals have available to take part in meaningful engagement is diminishing, and this in turn has led to channels of communication with diverse, "hard to reach" communities becoming increasingly narrow and tokenistic. This is despite the fact that engagement with these communities forms a key theme within much of the policy guidance around hate crime (College of Policing, 2014; HM Government, 2014, 2012; ODIHR, 2009). With levels of hate crime escalating, and awareness of and confidence in the support provided by public-sector agencies deteriorating, it is imperative that scholars and professionals take meaningful steps to connect with those communities who are most vulnerable to targeted hostility and to develop more effective awareness-raising campaigns which are tailored to the needs and experiences of specific groups.

\section{Problems in relation to existing interventions}

Although prima facie improvements have been made within the domain of criminal justice which include greater consistency in the recording of hate incidents across police forces, the introduction of hate crime laws across all monitored strands and the publishing of strategies and guidance notes by criminal justice agencies across England and Wales (Walters and Brown, 2016; Crown Prosecution Service, 2016; College of Policing, 2014; Law Commission, 2014), evidence suggests that these developments have yet to generate significant benefits for hate crime victims. Findings from the CSEW indicate that victims of hate crime are far less satisfied with the response that they receive from criminal justice agencies when compared to other forms of crime, with 52 per cent of hate crime victims very or fairly satisfied compared with 73 per cent of victims of non-hate offences, and 35 per cent very dissatisfied with the police handling of their case compared to 14 per cent of victims of other forms of crime (Corcoran et al., 2015). This was confirmed within each of our studies where criticisms of the initial response tended to stem from a feeling of not being listened to, not being taken seriously and not being treated with an appropriate level of decency.

Interviews revealed that problems encountered at the pre-reporting and initial response stages were compounded by what they perceived as a slow, intimidating and incomprehensible criminal justice system. We heard countless recollections of the difficulties that victims faced in relation to making sense of the complex, unfamiliar terminology used in reference to hate crime, of the relentless delays in waiting to receive any form of communication or follow-up, of the failure to keep victims informed on the progress of their case and of the lack of empathy shown by frontline practitioners working within the police service and other agencies including local authorities, housing associations and the Crown Prosecution Service (CPS). These factors exacerbate the harms associated with the original hate incident and cause added distress to victims, their families and wider communities. 
The appropriateness of prevailing criminal justice responses which are broadly punitive in nature have also been called into question. Hall (2013), for instance, observes that prison has limited deterrent value to many hate crime offenders, that such environments are often breeding grounds for intolerance and hostility and that the overcrowded and constrained conditions within many prisons offer scant opportunity for the kind of rehabilitation required to truly address prejudicial beliefs. Moreover, our own studies indicate that a preoccupation with punitive responses is at odds with the needs and expectations of hate crime victims who, despite assumptions to the contrary, often favour alternative educational interventions and restorative approaches to conventional criminal justice outcomes (Hardy and Chakraborti, 2016; Chakraborti et al., 2014). In our most recent study, for example, fewer than half (44 per cent; $n=131$ ) of participants referred to longer prison sentences as their preferred response to hate crime. Instead, 82 per cent $(n=246)$ called for greater use of tailored programmes of education within schools and local communities as a way of informing young people about positive aspects of diversity and the harms of hate crime, 55 per cent $(n=167)$ wanted to see more use of community "payback" orders for hate crime perpetrators and 32 per cent $(n=97)$ were in favour of more face-to-face supervised mediation between the victim and the offender (Hardy and Chakraborti, 2017). Crucially, those views were commonplace amongst victims of different types of violent and non-violent hate crime and from different communities, ages and backgrounds.

Despite the extended use of such interventions in the context of other criminal offences, their use in the context of hate crime remains relatively limited. Walters and Brown (2016, p. 21), for instance, refer to the CPS policy against the use of conditional cautions for hate crime and the failure of the 2016 Government Hate Crime Action Plan to even mention restorative justice as evidence of the resistance amongst some statutory agencies to endorse restorative interventions. Equally, although the same Action Plan names a selection of education programmes to evidence its support for early interventions, it is difficult to see how these programmes can deliver sustained success within the context of the many other complex challenges within schools and in the absence of wider investment to take the pressure of delivery away from teaching staff ill-equipped to engage pupils on issues relating to hate crime. Such indifference not only undermines the aims enshrined within national and local strategies, guidance documents and Action Plans to deliver effective hate crime responses but also the importance attached to addressing the needs and expectations of the many thousands of hate crime victims who are failing to receive adequate support from existing criminal justice interventions.

Preventative and rehabilitative interventions will only be effective when they are rooted in research evidence, and this reinforces the importance of learning from empirical research to generate a more comprehensive and sophisticated evidence base on hate crime perpetrators. Much of the academic undertaking within this field has focused upon the processes, forms and impacts of hate crime victimisation, with far less attention being paid to the motivations underpinning this form of perpetration. Crucially, once collected, this evidence needs to be shared amongst policy makers, practitioners, NGOs and other service providers who, collectively, will then be able to implement policies and programmes which are tailored to specific strands of hate crime, to different types of perpetrators and to pressure points within local areas.

\section{Conclusion}

This paper has identified a number of issues with current policy-level responses to hate crime which undermine their credibility in the eyes of victims. In particular, it has highlighted problems with levels of awareness and understanding amongst hate crime victims, with feelings of confidence in criminal justice agencies and partner organisations, with the uptake of support services and with the appropriateness and effectiveness of existing criminal justice interventions. All of these factors have the capacity to cause additional damage to the emotional and physical well-being of victims, and to reinforce the sense of powerlessness typically felt within groups who encounter targeted hostility as a routine feature of being "different".

This paper is not intended to overlook the good practice that is taking place across different sectors, or the professionalism of many practitioners across different sectors who work in increasingly pressured environments and remain committed to addressing problems associated 
with hate crime. Rather, it is designed to offer honest reflection on the shortcomings which constrain the effectiveness of responses to hate crime and to identify ways in which we can begin to address these shortcomings. In the context of prevailing economic, political and social conditions which act as enabling factors for the denigration of "marginal" communities, and with levels of hate crime continuing to surge both within the UK and beyond, it is imperative that scholars, policy makers, professionals, communities and individual citizens embrace their collective responsibility to challenge all forms of prejudice and hatred and to provide support to those most in need.

\section{Note}

1. A total of 33 research participants in the Hertfordshire-based study completed a questionnaire survey and also took part in an interview.

\section{References}

Awan, I. and Zempi, I. (2017), "I will blow your face off' - virtual and physical world Anti-Muslim hate crime”, British Journal of Criminology, Vol. 57 No. 2, pp. 362-80.

BBC News (2017), "Record hate crimes after EU referendum", available at: www.bbc.co.uk/news/amp/ 38976087 (accessed 5 June 2017).

Campbell, R. (2014), "Not getting away with it: linking hate crime and sex work in merseyside", in Chakraborti, N. and Garland, J. (Eds), Responding to Hate Crime: The Case for Connecting Policy and Research, The Policy Press, Bristol, pp. 55-70.

Chakraborti, N. and Garland, J. (2012), "Reconceptualising hate crime victimization through the lens of vulnerability and 'difference'”, Theoretical Criminology, Vol. 16 No. 4, pp. 499-514.

Chakraborti, N. and Garland, J. (2015), Hate Crime: Impacts, Causes and Consequences, 2nd ed., Sage, London.

Chakraborti, N. and Hardy, S. (2015), LGB\&T Hate Crime Reporting: Identifying Barriers and Solutions, Manchester, Equality and Human Rights Commission, London.

Chakraborti, N., Garland, J. and Hardy, S. (2014), The Leicester Hate Crime Project: Findings and Conclusions, University of Leicester, Leicester.

College of Policing (2014), Hate Crime Operational Guidance, College of Policing, Coventry.

Corcoran, H. and Smith, K. (2016), Hate Crimes, England and Wales, 2015/16, Home Office, London.

Corcoran, H., Lader, D. and Smith, K. (2015), Hate Crimes, England and Wales, 2014/15, Home Office, London.

Crown Prosecution Service (2016), Hate Crime Report 2014-15 and 2015-16, Crown Prosecution Service, London.

Garland, J. and Hodkinson, P. (2015), "Alternative subcultures and hate crime”, in Hall, N., Corb, A., Giannasi, P. and Grieve, J. (Eds), The Routledge International Handbook of Hate Crime, Routledge, London, pp. 226-36.

Hall, N. (2013), Hate Crime, 2ne ed., Routledge, London.

Hardy, S. and Chakraborti, N. (2016), "Healing the harms: identifying how best to support hate crime victims", available at: http://hertscommissioner.org/fluidcms/files/files/pdf/Victims-Commissioning/Healing-theHarms-Final-Report.pdf (accessed 1 May 2017).

Hardy, S. and Chakraborti, N. (2017), A Postcode Lottery? Mapping Support Services for Hate Crime Victims, University of Leicester, Leicester.

HM Government (2012), Challenge It, Report It, Stop It: The Government's Plan to Tackle Hate Crime, HM Government, London.

HM Government (2014), Challenge It, Report It, Stop It: Delivering the Government's Hate Crime Action Plan, HM Government, London.

Home Office (2016), Action Against Hate: The UK Government's Plan for Tackling Hate Crime, Home Office, London. 
Iganski, P. and Lagou, S. (2015), "The personal injuries of 'hate crime' ", in Hall, N., Corb, A., Giannasi, P. and Grieve, J. (Eds), The Routledge International Handbook on Hate Crime, Routledge, London, pp. 34-46.

Law Commission (2014), "Hate crime: should the current offences be extended?", available at: www.gov.uk/ government/uploads/system/uploads/attachment_data/file/316099/9781474104852_Web.pdf (accessed 2 June 2017).

Mason-Bish, H. (2016), “'Get yer tits out': why misogynistic street harassment is a crime”, available at: www.internationalhatestudies.com/get-yer-tits-out-why-misogynistic-street-harassment-is-a-hate-crime/ (accessed 1 May 2017).

Office for Democratic Institutions and Human Rights (ODIHR) (2009), Hate Crime Laws: A Practical Guide, ODIHR, Warsaw.

Perry, B. (2001), In the Name of Hate: Understanding Hate Crimes, Routledge, London.

Walters, M. and Brown, R. (2016), Preventing Hate Crime: Emerging Practices and Recommendations for the Improved Management of Criminal Justice Interventions, University of Sussex, Brighton.

\section{Further reading}

Hardy, S. (2017), "Everyday Multiculturalism and 'Hidden' Hate”, Palgrave Macmillan, London.

\section{Corresponding author}

Neil Chakraborti can be contacted at: nac5@le.ac.uk

For instructions on how to order reprints of this article, please visit our website: 